\title{
Evidências do ENADE - mudanças no perfil do matemático graduado
}

Kaizô Iwakami Beltrão*

Mônica Cerbella Freire Mandarino Mandarino**

\section{Resumo}

Este estudo tem como objetivo contribuir para as reflexões sobre políticas públicas referentes aos cursos de graduação em Matemática com um diagnóstico sobre: evolução da oferta, perfil dos concluintes e sua colocação no mercado de trabalho. Para isso, recorremos aos dados do INEP (Instituto Nacional de Estudos e Pesquisas Educacionais Anísio Teixeira) e do IBGE (Instituto Brasileiro de Geografia e Estatística). Observou-se que o aumento da oferta não foi acompanhado pela procura de formação na área, além de a razão entre número de matrículas e de concluintes ser baixa. Para descrição do perfil socioeconômico dos concluintes, recorremos à Análise de Componentes Principais, com dados de todos os concluintes das áreas que realizaram o ENADE (Exame Nacional de Desempenho dos Estudantes do Ensino Superior), de 2004 a 2011. Com os fatores obtidos, mostramos que os concluintes de Matemática estão entre os que possuem, em média, menor afluência socioeconômica dentre as áreas de conhecimento avaliadas pelo ENADE. Existe, também, uma diferença entre os graduados em Bacharelado e em Licenciatura, estes últimos menos afluentes. Por fim, a pesquisa amostral do Censo 2010 permitiu detectar que o magistério é a carreira da maioria dos matemáticos, principalmente os do sexo feminino, mas também mostra que muitos atuam em atividades de nível médio ou não afins com a área. Este estudo é facilmente replicável para outras áreas do conhecimento.

Palavras-chave: Ensino Superior. Matemática. Perfil socioeconômico. Mercado de trabalho.

\section{Introdução}

No Brasil, a década de 1990 foi marcada pela implantação de levantamentos de dados educacionais por meio de censos e avaliações nacionais. A continuidade e o investimento para a coleta de dados só faz sentido se, de alguma forma, eles forem usados em políticas para a melhoria da educação. Afinal, ninguém coleta dados

*Doutor em Estatística. Professor da EBAPE/FGV e Consultor Estatístico da Fundação Cesgrario.

**Doutora em Educação. Especialista em medidas educacionais da Fundação Cesgranrio. 
apenas para exibi-los. Os resultados da avaliação, por exemplo, devem possibilitar a melhoria dos processos de ensino e de aprendizagem. Para isso, é preciso que os dados e suas análises sejam entendidos pelos usuários em potencial. Em sintonia com Patton (1997), a utilização de resultados se refere a como pessoas reais, no seu contexto real, aplicam os resultados e vivenciam o processo avaliativo.

OBrasil possui uma característica peculiar que é o fato de o Governo Federal implantar levantamentos de dados educacionais a nível nacional, gerar e disponibilizar grandes bases de dados como os Censos Educacionais (desde 1980), e avaliações nacionais (desde 1990 - primeira edição do Saeb). Desde o final da década de 1990¹, esses tipos de levantamento vêm sendo ampliados para todos os níveis e modalidades de ensino, além de terem ocorrido levantamentos especiais como o Censo do Professor (1997 e 2003), o Censo da Educação Profissional (1999) e o Censo Escolar Indígena (1999). Existe, hoje, uma vasta gama de dados que podem ser utilizados para fins que extrapolam o desenho inicial do processo. O próprio governo tem incentivado, por meio do Observatório da Educação (BRASIL, 2006), a utilização destes dados e resultados em estudos e pesquisas, uma vez que disponibiliza para população em geral os microdados referentes a diferentes coletas de dados que vem conduzindo.

Neste estudo, apresentamos uma possibilidade de utilização dos dados do Censo da Educação Superior (de 1995 a 2010), do ENADE (de 2004 a 2011) e da pesquisa amostral do Censo Populacional (2010) para compreender a evolução dos cursos de graduação em Matemática, caracterizar o perfil dos concluintes e a posição dos matemáticos no mercado de trabalho, porsexo e faixa etária. Somentenas informações do ENADE, foi possível a diferenciação entre Bacharelado e Licenciatura. Estudo semelhante poderia ser realizado para outras áreas de formação.

Por meio dessas informações, buscamos responder às questões: houve evolução na oferta de profissionais na Área? De que forma? Essa trajetória foi diferente para os concluintes de Licenciatura e Bacharelado? Como evoluiu o perfil dos que terminaram o curso em 2005, 2008 e 2011? Qual a ocupação principal no mercado de trabalho dos Matemáticos em 2010, por sexo e faixa etária?

\section{Metodologia}

Para responder às duas primeiras questões de pesquisa, recorremos aos dados disponibilizados pelo MEC/INEP² dos Censos da Educação Superior, de 1995 a 2010,

1 A partir de 1997 o Instituto Nacional de Estudos e Pesquisas Educacionais (Inep) foi reestruturado e transformado no órgão responsável pelos levantamentos censitários e de avaliação da educação brasileira.

2 Disponível em: < portal.inep.gov.br/basica-levantamentos-acessar>. Acesso em 10/03/2013. 
e do ENADE, de 2005, 2008 e 2011, anos em que a Área de Matemática foi avaliada. As bases de dados dos Censos da Educação Superior e do ENADE foram tratadas usando o SPSS (Statistical Package for Social Sciences), versão 22 para Windows.

Para os Censos da Educação Superior, filtramos os cursos de Matemática e buscamos descrever a evolução, ao longo do período, para o qual os dados estão disponíveis (1995 a 2010), das variáveis: número de cursos, número de matrículas do respectivo ano e de concluintes. As sinopses, também disponibilizadas pelo INEP, contribuíram para a conferência dos valores por nós encontrados. Os resultados deste estudo estão discutidos na Seção 3 deste artigo.

Com as bases do ENADE, buscamos caracterizar o perfil socioeconômico dos concluintes dos diversos cursos de graduação e de formação de tecnólogos que têm participado das edições do ENADE desde 2004. Para isso, recorremos ao questionário socioeconômico do estudante que, apesar de ter sofrido algumas alterações desde a primeira edição do ENADE, boa parte das 54 questões que compõem os questionários atuais (a partir de 2008) já estavam presentes nos anos anteriores. Escolhemos e testamos algumas destas questões, uniformizando as categorias de resposta, quando necessário, e transformando-as, de variáveis ordinais em numéricas, por meio da técnica conhecida como Escalamento Ótimo (Optimal Scaling), disponível no SPSS. A seguir, utilizando as bases de dados de todas as Áreas, de todas as edições do ENADE, aplicamos a Análise de Componentes Principais (ACP) do SPSS às variáveis já uniformizadas e quantificadas. O objetivo foi obter fatores determinantes do perfil do aluno usando um número menor de variáveis, os fatores, que se constituem como combinação linear das variáveis iniciais, e explicam a maior parte da variância ${ }^{3}$. As variáveis do questionário utilizadas para $\mathrm{o} \mathrm{ACP}$ foram escolaridade da mãe e do pai, renda familiar, jornada de trabalho, independência econômica, número de corresidentes e tipo de escola onde o concluinte cursou o Ensino Médio. Assim, foram identificados três fatores de caracterização do perfil dos alunos; fator 1: afluência socioeconômica, que compõe-se pela escolaridade dos pais, escola onde o concluinte cursou o ensino médio e renda familiar; fator 2: autonomia financeira, com maior carga de jornada de trabalho e independência financeira; e, por último, o fator 3, que é explicado principalmente pelo número de familiares corresidentes, apesar de ser também influenciado pela renda familiar. Discutimos

3 Mais detalhes podem ser obtidos no Relatório Técnico "Perfil Socioeconômico dos Concluintes de Cursos Superiores de 2004 a 2011" (Beltrão et al, 2013). 
o perfil dos graduandos em Matemática em função destes fatores e os comparamos com os valores médios dos concluintes de outras Áreas na Seção 4.

Finalmente, recorremos à base de dados da pesquisa amostral do Censo-2010 ${ }^{4}$ para investigar a ocupação principal dos recenseados que declararam ter a maior formação na área de Matemática: graduação, mestrado ou doutorado. Para estes, levantamos sexo, idade, trabalho principal e ocupação. Para o IBGE, trabalho principal foi considerado como:

o único trabalho que a pessoa tinha na semana de referência. Para a pessoa que tinha mais de um trabalho na semana de referência, ou seja, para a pessoa ocupada em mais de um empreendimento nessa semana, adotaram-se os seguintes critérios, na ordem enumerada, para definir o principal: $1^{\circ}$ ) $\mathrm{O}$ trabalho principal era aquele ao qual a pessoa habitualmente dedicava maior número de horas por semana; $2^{\circ}$ ) No caso de igualdade no número de horas trabalhadas, o trabalho principal era aquele que proporcionava habitualmente o maior rendimento mensal; $\mathrm{e} 3^{\circ}$ ) No caso de igualdade, também, no rendimento, o trabalho principal era aquele com mais tempo de permanência no empreendimento, contado até o último dia da semana de referência. (IBGE, 2012, p. 36).

Já a ocupação é referenciada ao trabalho principal e considerou-se como ocupação a função, cargo, profissão ou ofício exercido pela pessoa. Para a classificação das ocupações utilizou-se a Classificação de Ocupações para Pesquisas Domiciliares - COD, que foi desenvolvida pelo IBGE, tendo como referência a International Standard Classification of Occupations - ISCO-08, da Organização Internacional do Trabalho - OIT (BRASIL, 2012, p. 37). A análise da colocação dos graduados, mestre e doutores em Matemática, por sexo e faixa, é discutido na Seção 5.

\section{Evolução na oferta de cursos de Matemática}

Com o estímulo do governo federal ao aumento da oferta de cursos de formação de professores, em todas as áreas, o número de cursos de Matemática, entre outros que oferecem habilitação em Licenciatura, vem se expandindo nos últimos 20 anos. Na Tabela 1, pode-se observar que o número de cursos de Matemática cresceu mais de 50\% em uma década, indo de um total de 402

4 Microdados da amostra do Censo 2010. 
cursos em 2000 a 676 em 2010. A expansão no número de cursos de Matemática no país não se deu de forma igual para as redes pública e privada. Na Tabela 1, pode-se observar que, de 1995 a 2010, a quantidade de cursos da rede pública aumentou em $258 \%$, com a maior taxa de crescimento de 2001 para 2002. Já na rede privada o aumento do número de cursos foi de $137 \%$, mas este quantitativo decresce depois de atingir o máximo de 318 cursos em 2007.

Na Tabela 1, pode-se observar, também, que os totais de matrículas e de concluintes seguiram uma trajetória um pouco diferente da evolução da oferta de cursos, atingindo um máximo em 2005 seguido de queda. No entanto, ao estratificar estes quantitativos por rede, observa-se que a queda no número total de matrículas é influenciada pela rede privada, já que na rede pública o número de matrículas apresenta uma tendência crescente no período. Já a queda no número total de concluintes ocorre nas duas redes: a partir de 2007 na rede privada e, já a partir de 2003, na pública. Apesar disso, ao longo do período em estudo (1995 a 2010), houve aumento no número total de matrículas $(100 \%)$ e de concluintes $(300 \%)$.

Conclui-se que a expansão na oferta não tem sido acompanhada por uma expansão proporcional do número total de matrículas e de concluintes, o que não contribui para o atendimento da demanda de expansão da Educação Básica.

Tabela 1 - Quantidade de cursos, matrículas e concluintes de cursos de graduação em Matemática no Brasil, segundo a rede de ensino - 1995 a 2010

\begin{tabular}{|c|c|c|c|c|c|c|c|c|c|c|c|}
\hline \multirow[t]{2}{*}{ Ano } & \multicolumn{3}{|c|}{$N^{\circ}$ de cursos } & \multicolumn{3}{|c|}{$\mathrm{N}^{\circ}$ de matrículas } & \multicolumn{3}{|c|}{$\begin{array}{l}\mathrm{N}^{\circ} \text { de concluintes } \\
\text { (ano anterior) }\end{array}$} & \multicolumn{2}{|c|}{$\begin{array}{l}\text { Razão entre } n^{\circ} \\
\text { de concluin- } \\
\text { tes e } n^{\circ} \text { de } \\
\text { matrículas do } \\
\text { mesmo ano }\end{array}$} \\
\hline & $\mathrm{Pu}$ & $\mathrm{Pr}$ & Tot & $\mathrm{Pu}$ & $\mathrm{Pr}$ & Tot & $\mathrm{Pu}$ & $\mathrm{Pr}$ & Tot & $\mathrm{Pu}$ & $\operatorname{Pr}$ \\
\hline 1995 & 116 & 110 & 226 & 20530 & 11275 & 31805 & 1492 & 1783 & 3275 & 0,072 & 0,112 \\
\hline 1996 & 132 & 94 & 226 & 20451 & 10408 & 30859 & 1473 & 1262 & 2735 & 0,111 & 0,126 \\
\hline 1997 & 111 & 89 & 200 & 22702 & 10210 & 32912 & 2279 & 1307 & 3586 & 0,108 & 0,138 \\
\hline 1998 & 147 & 108 & 255 & 23215 & 11721 & 34936 & 2460 & 1409 & 3869 & 0,098 & 0,164 \\
\hline 1999 & 181 & 133 & 314 & 25713 & 15774 & 41487 & 2270 & 1918 & 4188 & 0,086 & 0,175 \\
\hline 2000 & 229 & 173 & 402 & 29984 & 22402 & 52386 & 2209 & 2761 & 4970 & 0,085 & 0,129 \\
\hline 2001 & 239 & 194 & 433 & 32996 & 26109 & 59105 & 2560 & 2897 & 5457 & 0,109 & 0,161 \\
\hline 2002 & 331 & 197 & 528 & 36833 & 28396 & 65229 & 3591 & 4206 & 7797 & 0,174 & 0,169 \\
\hline 2003 & 338 & 212 & 550 & 39220 & 29699 & 68919 & 6392 & 4813 & 11205 & 0,159 & 0,180 \\
\hline
\end{tabular}

(continua) 


\begin{tabular}{l|l|l|l|l|l|l|l|l|l|l|l}
\hline 2004 & 332 & 240 & 572 & 39478 & 31380 & 70858 & 6242 & 5356 & 11598 & 0,158 & 0,202 \\
2005 & 331 & 274 & 605 & 40495 & 33694 & 74189 & 6229 & 6330 & 12559 & 0,131 & 0,191 \\
2006 & 337 & 294 & 631 & 40834 & 32680 & 73514 & 5307 & 6447 & 11754 & 0,129 & 0,197 \\
2007 & 314 & 318 & 632 & 42078 & 30320 & 72398 & 5287 & 6448 & 11735 & 0,119 & 0,197 \\
2008 & 322 & 313 & 635 & 42452 & 26093 & 68545 & 5001 & 5981 & 10982 & 0,116 & 0,226 \\
2009 & 350 & 285 & 635 & 41570 & 21091 & 62661 & 4930 & 5894 & 10824 & 0,122 & 0,200 \\
2010 & 415 & 261 & 676 & 45518 & 17130 & 62648 & 5072 & 4221 & 9293 & - & - \\
\hline
\end{tabular}

FONTE: INEP 2010).

A expansão constante da quantidade de cursos e de alunos, como seria de se esperar, tem sido acompanhada pela amplificação dos problemas do ensino universitário de Matemática, conhecidos desde muito tempo, e que sempre resultam, por exemplo, numa alta evasão. Como se observa na Tabela 1, a razão entre número de concluintes e de matriculados varia entre 0,073 em 1995 na rede pública e 0,229 em 2008 na rede privada, quando a razão esperada seria 0,25 em um fluxo ideal, considerando-se em curso de quatro anos.

Além disso, ao longo destes anos, as dificuldades dos alunos na transição do Ensino Médio para o Superior também aumentaram, devido à crise na Educação Básica (CURY, 2010; HADDAD, 2005; MACHADO, 2007). Este quadro tem exigido muita reflexão e mudanças curriculares e pedagógicas, em especial nos cursos de Licenciatura em Matemática, tanto por iniciativa do Conselho Nacional de Educação (CNE), ao propor novas diretrizes, quanto das Instituições de Ensino Superior (IES). $\mathrm{Na}$ última década, a comunidade de educadores matemáticos tem se reunido em Fóruns Nacionais de Licenciatura ${ }^{5}$, organizados pela Sociedade Brasileira de Educação Matemática (SBEM), para discutir e propor soluções para melhoria da formação de professores de Matemática. Segundo Pallis (2008) mudanças precisam ocorrer, devido a fatores vários: o rápido desenvolvimento das tecnologias computacionais; os apelos por integração com outras disciplinas, por iniciativas de inclusão e diversidade, pelo emprego de múltiplas formas de avaliação, pelo trabalho em grupo, etc. No entanto, mudanças na área educacional, em geral, demandam tempo.

Como em diversos outros fenômenos educacionais, o aumento total da quantidade de cursos, com maior contribuição dos públicos, tem várias razões.

5 I FÓRUM realizou-se em junho de 2004 na PUC-SP; o II FÓRUM em dezembro de 2007 na UNICAMP; o III FÓRUM em outubro de 2009, na PUC-DF, em Taguatinga; e o IV FÓRUM abril de 2011 na FE/USP. 
É possível que uma delas seja o crescimento do número de candidatos em potencial para o Ensino Superior. Outra pode estar associada ao aumento da necessidade de professores de Matemática para a Educação Básica e uma terceira diretamente ligada às políticas de expansão das IES públicas, desde o início dos anos 2000. Em menor escala, ainda é possível supor que tal aumento esteja relacionado com o aumento de mercado de trabalho para o matemático, ultrapassando os muros da escola e se firmando em áreas ligadas à tecnologia da informação e ao mercado financeiro. De qualquer forma, no momento atual do país, é difícil imaginar crescimento social e industrial sem que haja melhoria na formação de profissionais, o que inclui a formação de professores e aqueles da área de matemática aplicada. Já o descompasso de tal crescimento em relação à quantidade de formandos precisa ser analisado em outros parâmetros, um deles, sem dúvida, é o perfil dos alunos.

\section{0 perfil dos concluintes}

O Ensino Superior começa a ser avaliado em 1996 pelo Exame Nacional de Cursos (ENC), também conhecido como PROVÃO. Em 2004, o PROVÃO foi substituído pelo ENADE e a avaliação do Ensino Superior passa também a incluir a Análise das Condições de Oferta e a Análise das Condições de Ensino. O ENADE surge com uma nova concepção, mas mantém o propósito de avaliar Instituições de Ensino Superior a partir do desempenho de seus estudantes.

O Exame Nacional de Desempenho dos Estudantes (ENADE), como parte integrante do SINAES, foi definido pela [Lei no 10.861 , de 14 de abril de 2004], conforme a perspectiva da avaliação dinâmica que está subjacente ao SINAES. O ENADE tem por objetivo geral aferir o desempenho dos estudantes em relação aos conteúdos programáticos previstos nas diretrizes curriculares da respectiva Área de graduação, suas habilidades para ajustamento às exigências decorrentes da evolução do conhecimento e suas competências para compreender temas exteriores ao âmbito específico de sua profissão, ligados à realidade brasileira e mundial e a outras Áreas do conhecimento. (BRASIL, 2002).

Atualmente é consenso que a educação é uma necessidade e um direito de todo ser humano (UNESCO, 1998). Com essa perspectiva, o acesso às salas de aula aumentou significativamente no Brasil. No entanto, permanece o 
desafio de oferecer educação de qualidade, e a avaliação tem sido utilizada para gerar subsídios para a tomada de decisões na busca da melhoria. A avaliação é uma área do conhecimento ainda em desenvolvimento e, em uma de suas concepções contemporâneas (JOINT COMMITTEE ON STANDARDS FOR EDUCATIONAL EVALUATION, 1994), ela deve levantar informações pertinentes à qualidade de algo em mais do que uma dimensão. Scriven (1981) aponta duas: o mérito (qualidade intrínseca) e o valor ou relevância (qualidade extrínseca). No caso do Ensino Superior, é importante avaliar um curso em termos, por exemplo, de recursos humanos qualificados, instalações físicas adequadas e biblioteca devidamente equipada. Além disso, é preciso considerar até que ponto um curso tem relevância, principalmente, em termos da formação que os seus alunos adquirem, levando em conta as possibilidades de sua colocação no mercado de trabalho. É fundamental, ainda, ter um bom diagnóstico dos alunos, não apenas do ponto de vista cognitivo, já que o mérito em termos de recursos, por exemplo, só faz sentido se todos tirarem o melhor proveito deles.

Neste trabalho, trazemos um diagnóstico socioeconômico dos alunos dos cursos de Matemática construído a partir de alguns itens do questionário socioeconômico respondido pelos concluintes nos anos de aplicação do $\operatorname{ENADE~(2005,~2008,~}$ 2011). Segundo o Manual do ENADE, "a participação na pesquisa desenvolvida por meio do Questionário do Estudante é de grande relevância para o conhecimento do perfil do estudante avaliado pelo Sinaes.” (BRASIL, 2012, p.16).

Conforme já apresentado, obtivemos três fatores para caracterizar o perfil socioeconômico dos concluintes dos cursos superiores participantes do ENADE, de 2004 a 2011. Para cada Área de graduação, foi obtido o escore médio das três dimensões (fatores) com respeito a todos os alunos concluintes. Usamos estes valores para representar graficamente todas as Áreas nas dimensões já citadas (Gráficos 1 e 2), a saber: fator 1 - afluência socioeconômica, fator 2 - autonomia financeira, fator 3 - corresidência.

No Gráfico 1 foram assinaladas em vermelho as Áreas que, além de oferecerem, na maioria dos casos, habilitações como o Bacharelado, formam professores das tradicionais disciplinas da Educação Básica. Dentre elas, destacamos a Matemática. As demais Áreas classificadas em uma mesma grande Área pelo INEP estão apresentadas com uma mesma cor. As linhas pontilhadas $(x+y= \pm 0,8)$ delimitam a nuvem de pontos e ajudam a evidenciar que cada acréscimo do fator 1 (afluência 
socioeconômica) corresponde a um decréscimo no fator 2 (autonomia financeira) de aproximadamente mesma magnitude, ainda que a faixa possível de variação seja ampla. As origens dos eixos correspondem à média do fator na população.

Observa-se que para todos os concluintes das Áreas fortemente marcadas pela formação de professores, o fator 1 - afluência socioeconômica - está abaixo da média: Normal Superior, Pedagogia, Matemática, Letras, Geografia, História, Filosofia, Química, Física e Biologia, em ordem crescente deste fator. Logo, a afluência socioeconômica dos concluintes de Matemática é a terceira mais baixa, à frente apenas dos graduandos em Pedagogia e Normal Superior. Do ponto de vista da autonomia financeira, os concluintes de Matemática são dos mais independentes dentre as Áreas de formação de professores, com fator 2 acima da média, superado apenas pelos concluintes de Normal Superior. Comparando-se a Matemática com outras Áreas das Ciências Exatas e Tecnológicas, observa-se que os concluintes de Matemática possuem, em média, menos autonomia financeira do que os dos cursos que formam tecnólogos e afluência socioeconômica média menor do que a dos concluintes das Engenharias. Destacamos, ainda, que as três Áreas com concluintes de maior afluência socioeconômica são, em ordem crescente deste fator, Arquitetura e Urbanismo, Relações Internacionais e Medicina. Já a Área com concluintes que possuem maior autonomia financeira média é Tecnologia em Gestão da Produção Industrial. Outras análises podem ser encontradas em Beltrão et al. (2013).

\section{Gráfico 1 - Valores médios dos fatores 1 e 2 segundo Área - ENADE 2004-2011}

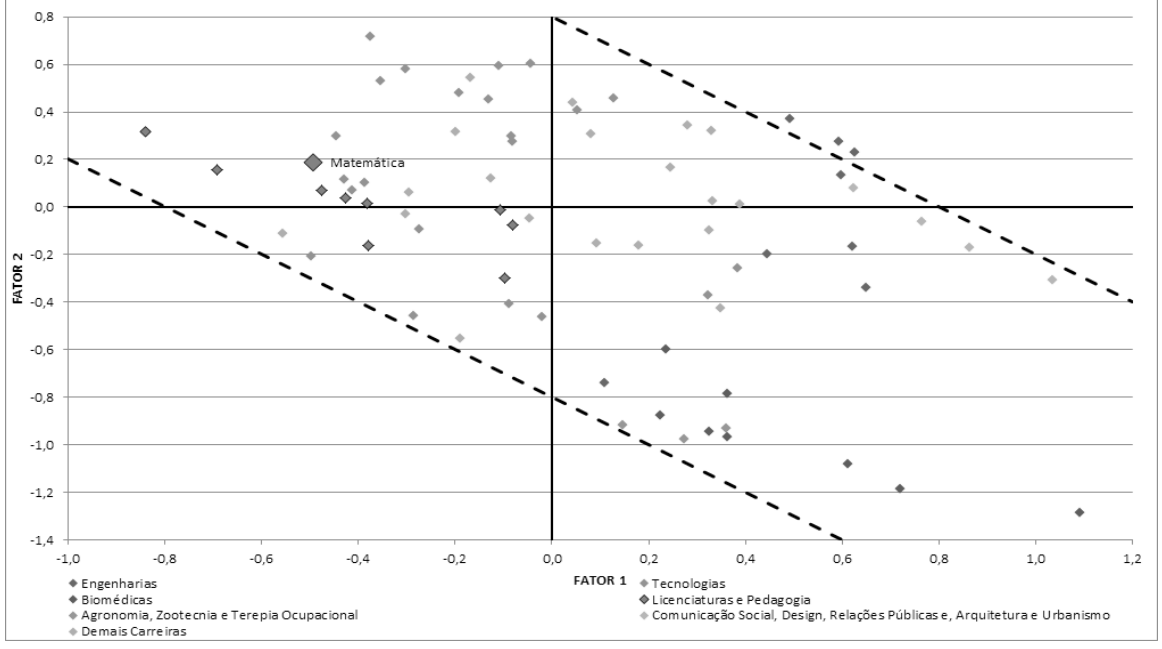


Fonte: Os autores (2014).

No Gráfico 2 estão representados somente os valores médios de alunos concluintes da área de Matemática (fator 1 no eixo das abcissas e fator 2 no eixo das ordenadas), mas desagregados por ano calendário e pela dicotomia Licenciatura/Bacharelado. Tipicamente, os pontos relativos ao Bacharelado estão localizados mais à direita e mais abaixo, indicando maior afluência socioeconômica e menor autonomia financeira destes quando comparados com os alunos de Licenciatura. O movimento temporal foi de aumento do distanciamento com respeito à afluência socioeconômica entre os alunos de Licenciatura e de Bacharelado (ainda que possa existir uma intersecção entre eles): valores médios do fator 1 vão aumentando no tempo para os alunos de Bacharelado e diminuindo para os alunos de Licenciatura. Os alunos de Bacharelado apresentam, em 2011, um valor muito menor de autonomia financeira com o ponto já no quarto quadrante. Concomitante com este movimento temporal de aumento da afluência socioeconômica e diminuição da autonomia financeira, os alunos de Bacharelado passaram a apresentar um perfil etário mais jovem, na contramão da inclusão universitária que passou a incorporar contingentes mais velhos. Este foi o caso dos alunos de Licenciatura, com um perfil etário mais velho com o passar do tempo.

Gráfico 2 - Valores médios dos fatores 1 e 2 para Matemática segundo ano e indicação de Bacharelado/Licenciatura - ENADE 2004-2011 


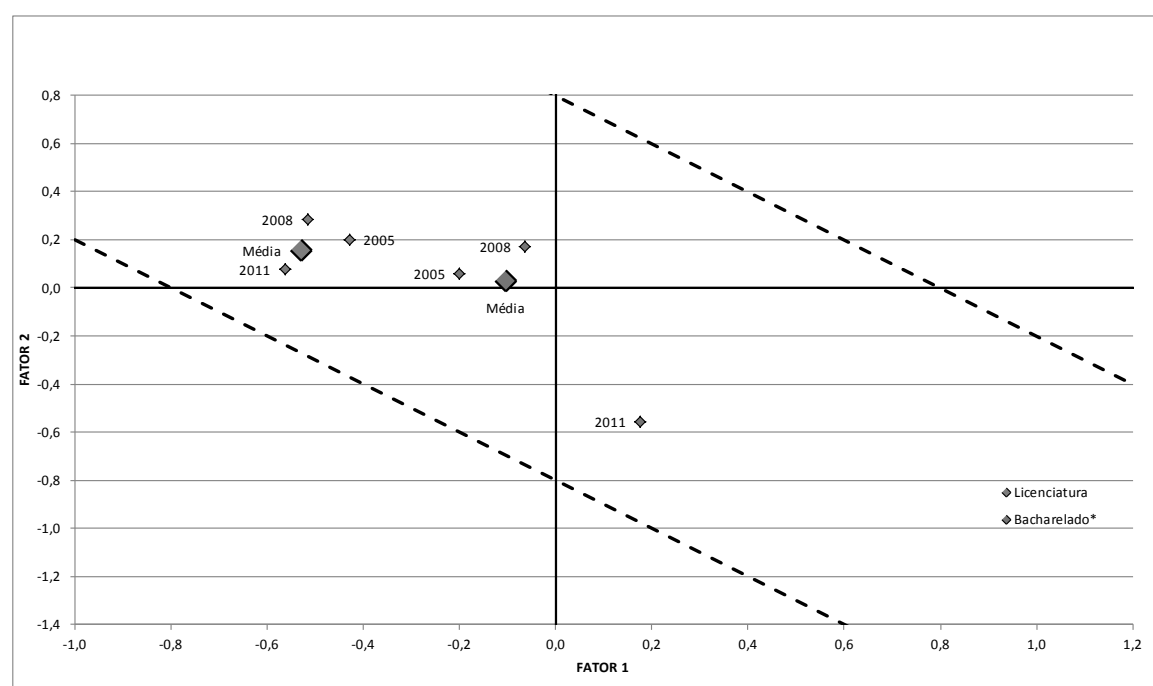

Fonte: Os autores (2014).

No Gráfico 3 a abscissa é a mesma do Gráfico 1, fator 1 - afluência socioeconômica média dos concluintes da Área. A ordenada mostra as médias dos concluintes das diferentes Áreas em relação ao fator 3 (corresidência familiar), fator com carga do tamanho da família e, em menor grau, da renda familiar. Nota-se que o fator 3 dos concluintes de Matemática está um pouco acima da média de todos os cursos, abaixo apenas das médias dos graduandos em Pedagogia e Normal Superior, dentre as demais Áreas assinaladas em vermelho. As Áreas com médias do fator 3 mais baixas são Filosofia, no $3^{\circ}$ quadrante, e, no $4^{\circ}$ quadrante, Zootecnia, Teatro e Medicina, em ordem crescente do fator 1. Já os concluintes com média do fator 3 mais alta são os dos cursos de Tecnologia em algum tipo de Gestão (Recursos Humanos, Hospitalar, Produção Industrial, Processos Gerenciais, Financeira), no $2^{\circ}$ quadrante, e Tecnologia em Gastronomia no $1^{\circ}$ quadrante.

Gráfico 3 - Valores médios dos fatores 1 e 3 segundo Área - ENADE 2004-2011 


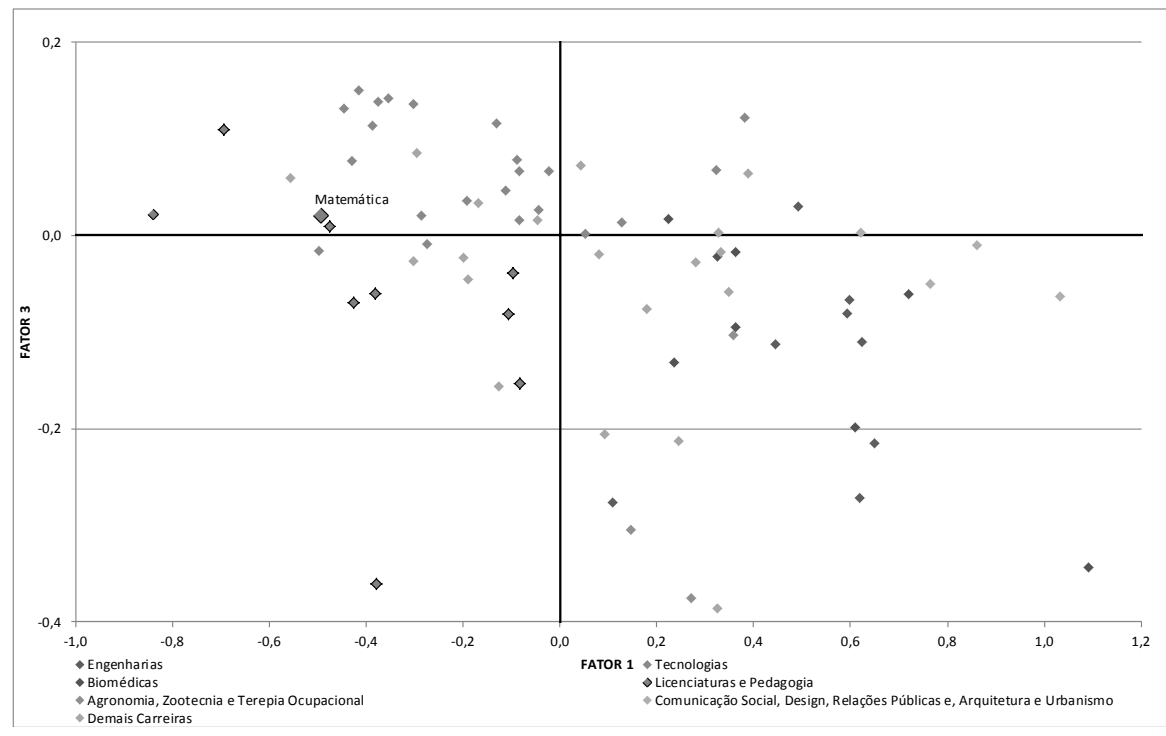

Fonte: Os autores (2014).

No Gráfico 4 estão representados somente os valores médios de alunos concluintes da área de Matemática (fator 1 no eixo das abcissas e fator 3 no eixo das ordenadas), mas desagregados por ano calendário e pela dicotomia Licenciatura/Bacharelado. Tipicamente os pontos relativos ao Bacharelado estão localizados mais à direita e mais abaixo, indicando uma maior afluência socioeconômica e um menor fator de corresidência.

Gráfico 4 - Valores médios dos fatores 1 e 3 para Matemática segundo ano e Bacharelado/Licenciatura - ENADE 2004-2011 


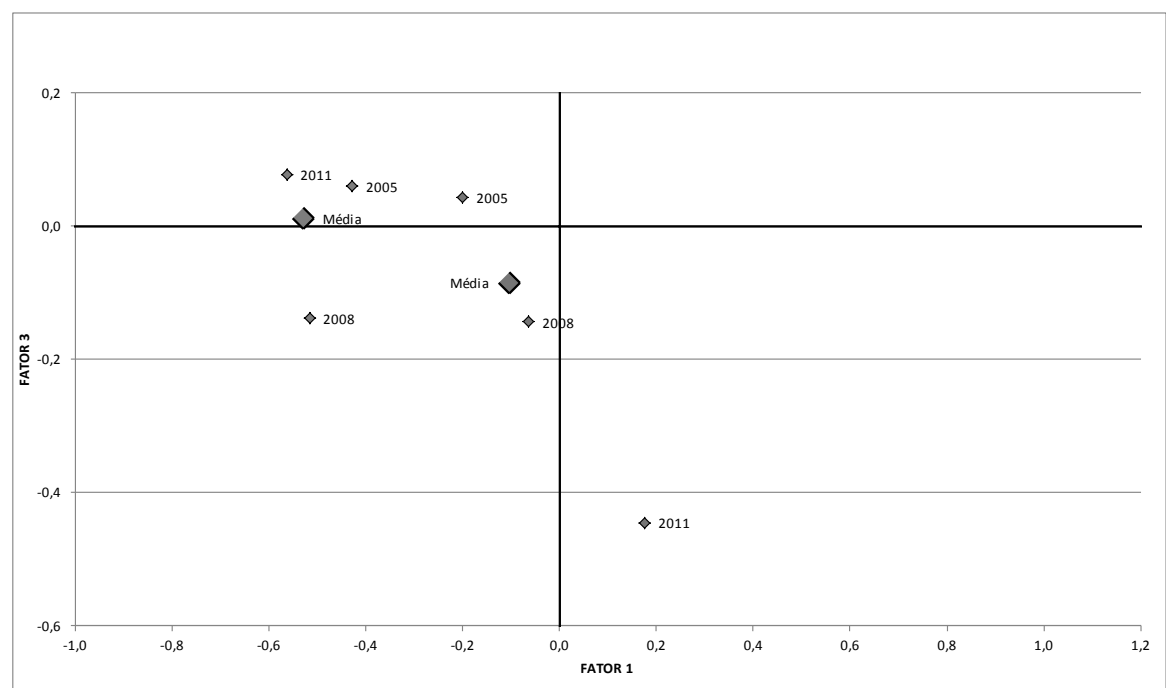

Fonte: Os autores (2014).

Pode-se concluir que os alunos de Licenciatura em Matemática, no final de sua formação, em média, já estão colocados no mercado de trabalho, vêm de famílias não muito grandes, com pouca escolaridade e renda familiar abaixo da média dos estudantes de cursos superiores. Nota-se uma queda na afluência socioeconômica com o tempo. Os graduados em Bacharelado em Matemática são, em média, mais afluentes que os seus contrapartes de Licenciatura e têm apresentado uma melhora no tempo, principalmente no último triênio analisado.

\section{A atuação profissional dos graduados, mestres e doutores em Matemática}

Usando dados da amostra do Censo 2010 sobre ocupação no trabalho principal, conforme definido na metodologia, traçamos o perfil profissional dos que declararam ter a Matemática como Área de maior formação (graduação ${ }^{6}$, mestrado ou doutorado). Inicialmente, detectamos uma grande diversidade de categorias de ocupação no trabalho principal, especialmente para os graduados, e uma categoria "não aplicável". A "não aplicável" foi usada pelo IBGE quando a pessoa não era economicamente ativa na semana de referência:

6 Não há diferenciação entre bacharelado ou Licenciatura na base de dados. 
pessoa que não era ocupada e nem desocupada (sem trabalho, mas que estava disponível para assumir um trabalho e que tomou alguma providência efetiva para conseguir trabalho) (BRASI, 2012, p.35). Também são computados nesta categoria os aposentados e os estudantes.

Criamos a categoria "outros" para os diversos tipos de ocupação no trabalho principal que não exigem formação em Matemática e, quase sempre, tinham frequência bem pequena. Dentre os graduados, havia um grande número de ocupações que classificamos como "outros", algumas que sequer exigem nível superior. Por exemplo, 2,45\% dos 165.930 matemáticos graduados da amostra estavam atuando no comércio em 2010 (balconistas, vendedores, demonstradores, frentistas, etc.). Em "outros" havia, também, graduados com ocupação no trabalho principal que exigem alguma outra formação de nível superior, por exemplo, advogados ou juristas $(0,24 \%)$ e engenheiros $(0,28 \%)$, sugerindo uma dupla graduação.

Em seguida, agrupamos ocupações que exigem nível superior e têm alguma afinidade com a formação em Matemática, com o objetivo de reduzir a variabilidade de classificações e facilitar tanto a representação gráfica, quanto a interpretação da informação. Para isso, levamos em conta grandes áreas do mercado de trabalho: militar, gestão em serviços, financeira/atuarial, tecnologia da informação e educação (atividades não docentes). Por fim, decidimos não agrupar as categorias dos que atuam na docência, já que estas contém a maioria dos matemáticos que eram economicamente ativos na semana de referência em 2010.

Os gráficos a seguir mostram que, proporcionalmente, em 2010 havia mais homens (Gráfico 3A) ocupados em atividades classificadas como "outros" do que mulheres (Gráfico 3B), e que estas estavam bem mais envolvidas com o magistério ou outras atividades da área educacional. Destaca-se que na área financeira/atuarial a participação de graduados dos dois sexos em Matemática era semelhante, mas que os homens estavam mais presentes na área Militar. Chama atenção, ainda, que a proporção de mulheres com ocupação no trabalho principal classificada como "não aplicável" era maior que a dos homens a partir dos 25 anos, além de aumentar mais rapidamente com a idade.

Gráfico 3 - Distribuição da ocupação no trabalho principal entre graduados em Matemática segundo a faixa etária - 3A homens e 3B mulheres - Censo 2010 

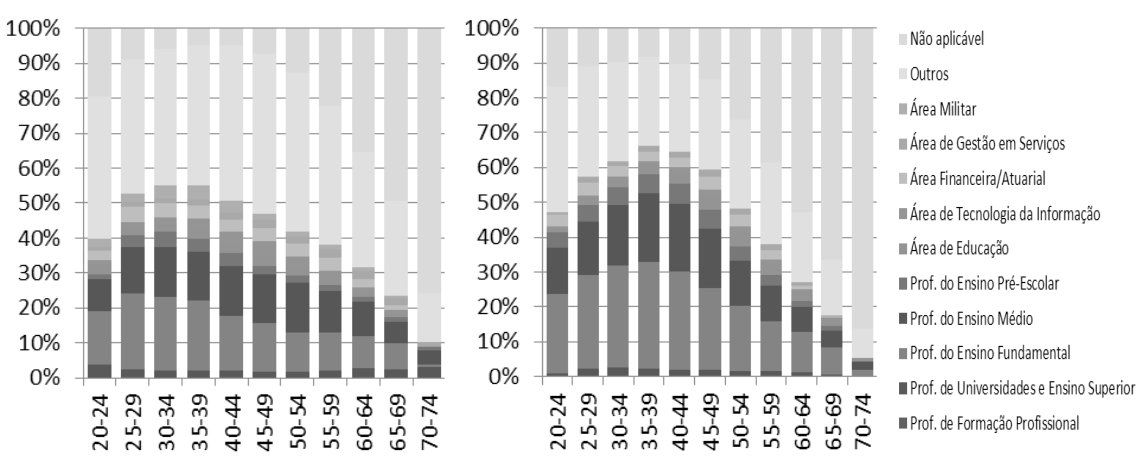

Fonte: Os autores (2014).

Diferentemente dos anteriores, nos Gráficos 4A e 4B a distribuição de homens e mulheres com mestrado em Matemática em 2010 é menos parecida. Nos dois sexos, o magistério era a principal ocupação, visto que havia mais homens na docência do Ensino Superior do que mulheres, estas mais presentes na Educação Básica (Fundamental e Médio). Talvez por isso, observam-se mais mulheres na categoria "não aplicável" do que homens nas faixas de idade mais elevadas, já que professores da Educação Básica se aposentam com 5 anos a menos do que outros profissionais. Entre os jovens mestres, até 29 anos, a proporção também significativa de "não aplicável" pode estar associada aos que seguem estudando para ou no doutorado. Comparando-se as demais áreas agrupadas observa-se que dentre os mestres havia mais homens na área de tecnologia da informação e mais mulheres na área financeira/atuarial.

\section{Gráfico 4 - Distribuição da ocupação no trabalho principal entre mestres em Matemática segundo faixa etária - 4A homens e 4B mulheres - Censo 2010}
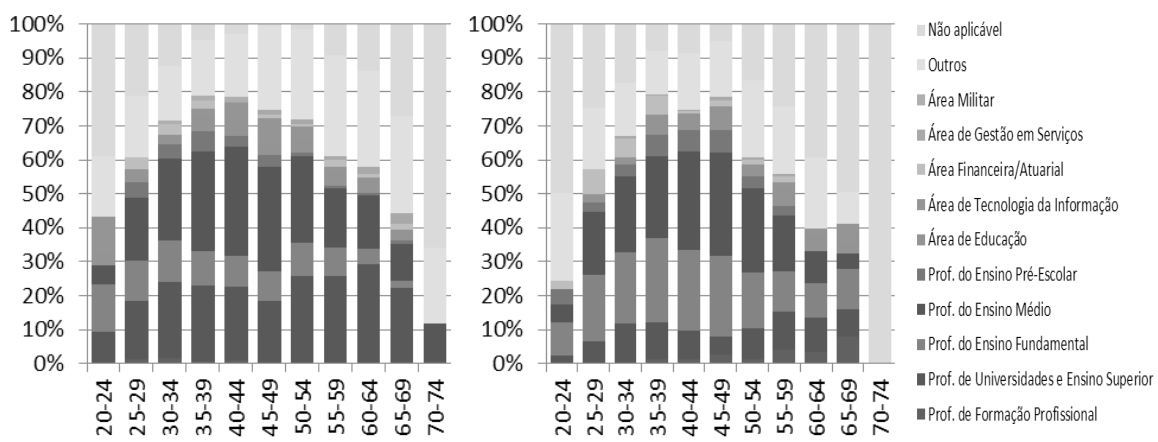

Fonte: Os autores (2014). 
Os Gráficos 5A e 5B mostram que os doutores em Matemática, homens ou mulheres, eram majoritariamente professores, preferencialmente atuando no Ensino Superior. Diferentemente dos casos anteriores, dentre os doutores, a proporção de homens trabalhando no Ensino Fundamental era maior do que a de mulheres e a proporção de mulheres era maior no Ensino Médio. As mulheres doutoras estão mais presentes na área de tecnologia da informação do que os homens nas faixas entre 40 e 50 anos. Nota-se, ainda, que entre os doutores havia uma proporção menor de pessoas atuando em atividades "outras" ou na categoria "não aplicável" do que dos mestres e graduados.

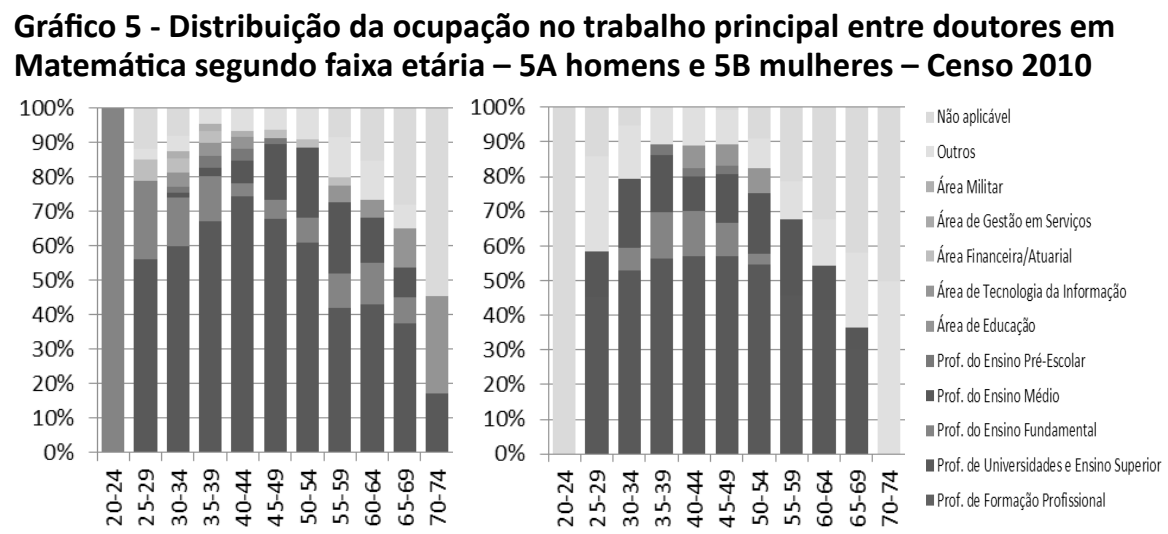

Fonte: Os autores (2014).

\section{Considerações Finais}

Dentro do limite deste artigo, trazemos um diagnóstico da evolução da oferta de cursos superiores de Matemática, sem diferenciação entre Licenciatura ou Bacharelado, do perfil socioeconômico dos concluintes e da colocação dos matemáticos, participantes da amostra do Censo 2010, no mercado de trabalho. Acreditamos que diagnósticos, como o aqui apresentado, podem contribuir para reflexões sobre políticas públicas associadas à oferta de cursos de graduação. Para os estudos na área de currículo é preciso considerar o contexto social e cultural no qual um sistema educacional está inserido, e os grupos sociais que dele se utilizam (SILVA, 1999). O diagnóstico aqui apresentado pode contribuir para a definição do perfil do profissional que se deseja formar, sobre a qual se sustentam as outras definições curriculares. Segundo Sacristán (2000), o currículo se configura como "um território político" e constitui-se, também, num ponto central de referência 
na melhora da qualidade do ensino, na mudança das condições da prática, no aperfeiçoamento dos professores, na renovação da instituição escolar em geral e nos projetos de inovação dos centros escolares (idem, p. 32).

Sem poder fazer uma diferenciação entre bacharéis e licenciados, vimos que a ocupação no trabalho principal mais recorrente é o magistério, alterando-se o nível de ensino onde atuam conforme aumenta seu grau de formação. A perspectiva de que a principal atuação é no ensino, com diferença no nível de escolaridade, pode ser encontrada nas "Diretrizes Curriculares Nacionais para os Cursos de Matemática, Bacharelado e Licenciatura" (BRASIL, 2001). Na introdução deste documento afirma-se que os cursos de Bacharelado em Matemática existem para preparar os profissionais para a carreira de Ensino Superior e pesquisa, enquanto os cursos de Licenciatura em Matemática têm como objetivo principal a formação de professores para a educação básica. (grifo nosso). Nesta afirmação observa-se, no entanto, o equívoco de que os bacharéis atuarão na pesquisa, o que stricto senso só ocorreria com a continuidade dos estudos na Pós-Graduação. Por outro lado, numa visão mais atual do campo da Educação, qualquer professor deveria ter formação para exercer uma postura investigativa, sendo pesquisador da própria prática. Ao mesmo tempo, se o Bacharel poderá atuar como professor, seguindo para a carreira de Ensino Superior, seria preciso incorporar à sua formação competências ligadas à formação do professor. De alguma forma, os alunos parecem diferenciar entre as escolhas de Bacharelado e Licenciatura, já que os perfis socioeconômicos dos graduados mostram um hiato que está se alargando: bacharéis estão tipicamente se tornando mais afluentes socioeconomicamente ao passo que licenciados, em média, estão se tornando mais pobres.

Por fim, o diagnóstico do perfil socioeconômico dos concluintes aponta para a necessidade de o projeto pedagógico da formação profissional, que deve ser elaborado pelos cursos de Matemática (BRASIL, 2013), garantir condições para que as competências e habilidades previstas nas Diretrizes Curriculares Nacionais sejam desenvolvidas de forma equânime por todos os alunos, independente das condições socioeconômicas prévias.

Agradecemos a Ricardo Servare Megahós e a Matheus Oliveira da Motta, estagiários da Fundação Cesgranrio e alunos da ENCE (Escola Nacional de Estatística), pela contribuição no tratamento das bases de dados e interlocução nas discussões para análise dos resultados. 


\section{Referências}

BELTRÃO, K. et al. Perfil Socioeconômico dos Concluintes de Cursos Superiores de 2004 a 2011. Rio de Janeiro: Fundação Cesgranrio, 2013. Mimeo.

BRASIL. Conselho Nacional de Educação. Parecer CNE/CES n. 1302 de 3 de novembro de 2001. Dispõe as Diretrizes Curriculares Nacionais para os Cursos de Matemática, Bacharelado e Licenciatura. Diário Oficial da União, Brasília, DF, 05 nov. 2001.

. Conselho Nacional de Educação. Resolução CNE/CES, n. 3 de 3 de outubro de 2013. Institui Diretrizes Curriculares Nacionais dos Cursos de Graduação em Matemática. Diário Oficial da União, Brasília, DF, 04 out. 2013. Seção 1, p. 57.

. Ministério da Educação. Manual do ENADE 2012. Brasília, DF: Inep, 2012.

. Ministério da Educação. Relatório Síntese do ENADE 2001. Brasília, DF: Inep, 2002.

. Decreto $n^{0} 5.803,8$ de junho de 2006. Dispõe sobre o Observatório da Educação, e dá outras providências. Diário Oficial da União, Brasília, DF, 9 jun. 2006. Disponível em: <http://www.planalto.gov.br/ccivil_03/_Ato20042006/2006/Decreto/D5803.htm.>. Acesso em: 10 fev. 2013.

CURY, C. R. J. Educação e crise: perspectivas para o Brasil. Educação e Sociedade, Campinas, v. 31, n. 113, p.1089-1098, out./dez. 2010. Disponível em: <http://www.cedes.unicamp.br>. Acesso em: 24 out. 2012.

HADDAD, F. A crise e os projetos da educação. 2005. Entrevista à assessoria de Comunicação Social do Ministério da Educação. Disponível em: $<$ http://portal. mec.gov.br/arquivos/pdf/acs_180805entrevista.pdf $>$. Acesso em: 24 out. 2012.

IBGE. Instituto Brasileiro de Geografia e Estatística. Censo Demográfico 2010: trabalho e rendimento: resultado da amostra. Rio de Janeiro: IBGE, 2012. CDROM. 
JOINT COMMITTEE ON STANDARDS FOR EDUCATIONAL EVALUATION. The program evaluation standards. 2nd ed. Thousand Oaks, CA: Sage Publications, 1994.

MACHADO, N. J. Qualidade da educação: cinco lembretes e uma lembrança. Estudos Avançados,[S.1], n. 21, v. 61, p. 277-294, 2007. Disponível em: $\quad<$ http://www.scielo.br/scielo.php?script=sci_arttext\&pid $=$ S0103-40142007000300018>. Acesso em: 24 out. 2012.

PALLIS, G. L. R. A pesquisa sobre a própria prática no Ensino Superior de Matemática. In: COLÓQUIO DE HISTÓRIA E TECNOLOGIA NO ENSINO DE MATEMÁTICA, 4., 2008, Rio de Janeiro. Anais... Rio de Janeiro: UFRJ, 2008. Disponível em: <http://limc.ufrj.br/htem4/papers/40.pdf>. Acesso em: 24 out. 2012.

PATTON, M. Q. Utilization-focused evaluation. 3rd ed. Thousand Oaks, CA: Sage. 1997.

SACRISTÁN, J. G. O. Currículo: uma reflexão sobre a prática. Porto Alegre: ArtMed, 2000.

SCRIVEN, M. S. Evaluation thesaurus. 3rd ed. Pt. Reyes, CA: Edgepress, 1981.

SILVA, T. T. da. Documentos de identidade: uma introdução às teorias do currículo. Belo Horizonte: Autêntica, 1999.

UNESCO. Organização das Nações Unidas (Brasil). Declaração dos Direitos Humanos, 1998.

\section{Evidences of ENADE - changes in the Mathematics graduates profile Abstract}

This study aims to contribute to the discussions on public policies concerning graduate courses in Mathematics with a diagnosis of: evolution of the supply, the profile of graduates and their placement in the labor market. For this, we used 
data from the INEP (National Institute of Educational Studies Anisio Teixeira) and IBGE (Brazilian Institute of Geography and Statistics). It was observed that the increase in supply was not accompanied by the interest in the area of mathematics, and the ratio between the number of enrollments and graduates is low. For description of the socioeconomic profile of students who complete the course we appealed to the Principal Component Analysis, with data from all areas of the graduates who took the ENADE (National Survey of Student of Higher Education Performance) 2004-2011. The factors obtained show that, on average, Mathematics graduates are among those socioeconomically less affluent among the areas evaluated by ENADE. One can also note a difference among those with a BA and those with a License (in Brazil, a BA in Math does not entitle a person to teach, a License is necessary. Students with BA go on to get MSc and PhD), the latter less affluent. Finally, the survey sample of the 2010 Census allowed detecting that the teaching is the career of most mathematicians, especially for women, but also shows that many operate in activities midlevel or not related to the area. This study is easily replicable for other areas.

Keywords: Higher Education. Mathematics. Socioeconomic profile. Labour market.

\section{Evidencias del ENADE - cambios en el perfil del matemático graduado Resumen}

Este estudio tiene como objetivo contribuir a los debates sobre el plan de estudios de los cursos de licenciatura en Matemáticas con diagnóstico sobre: tendencias en la oferta, el perfil de los graduados y su colocación en el mercado laboral. Para ello, hemos utilizado los datos de INEP (Instituto Nacional de Estudios de la Educación Anísio Teixeira) y de IBGE (Instituto Brasileño de Geografia y Estadística). Se observó que el aumento de la oferta no ha sido acompañado por la demanda de formación en matemáticas y la proporción entre la matrícula y los graduados es baja. Para la descripción del perfil socioeconómico de los graduados se utilizó el Análisis de Componentes Principales, con los datos de todos los graduados de las áreas que realizaron el ENADE (Encuesta Nacional sobre el Rendimiento de los Estudiantes de la Educación Superior) del 2004 al 2011. Los factores obtenidos muestran que los graduados de matemáticas se encuentran entre aquellos con menor riqueza socioeconómica. Hay aún una 
diferencia entre los alumnos de Grado Universitario y Profesorado, los últimos con menor grado de riqueza. Por último, la muestra del Censo 2010 permitió observar que la docencia es la carrera de la mayoría de los matemáticos, especialmente mujeres, y también muestra que muchos operan en actividades de nivel medio o no relacionadas con el área.

Palabras clave: Educación Superior. Matemáticas. Perfil socioeconómico. Mercado laboral. 